\title{
Expressed emotion of professionals towards mental health patients
}

\author{
GREET VAN HUMBEECK and CHANTAL VAN AUDENHOVE
}

\section{INTRODUCTION}

In rehabilitation programmes of clients with severe mental illnesses, professional caregivers have a crucial role, their main tasks being to provide and co-ordinate the needed care and to help the patients to come to terms with their illness. However, it is not always easy to be a good counsellor for these clients. Although professional caregivers have their professional backgrounds to rely on, many often confront excessive occupational stress and sometimes feel emotionally exhausted (Dietzel \& Coursey, 1998; Reid et al., 1999). Like family members, they have to cope with a broad range of problematic behaviour such as verbal abuse, acting-out, aggression, positive symptoms and serious neglect. Clients with mental illnesses often need long-term care. Progress is difficult and relapses are not exceptional. Frequently, professional caregivers have to find out by trial and error what interventions work and what might not and may well feel that they are not appreciated by the clients (Kuipers \& Moore, 1995). As a result, caregivers may become disappointed, dissatisfied, frustrated, and discouraged and even burn out. These feelings may then affect their clients, causing them to become confused and to end counselling (Finch \& Krantz, 1991).

In this article, we will first focus on the professional caregivers' attitudes towards clients with a severe mental

Address for correspondence: Professor Ch. Van Audenhove, LUCAS - K.U.Leuven, Kapucijnenvoer 35, B-3000 Leuven (Belgium). Fax: +32-(0) 16-336.922

E-mail: Chantal.Vanaudenhove@med.kuleuven.ac.be

E-mail: Greet.Vanhumbeeck@med.kuleuven.ac.be

Declaration of Interest: This research was financed by a grant from the Research Fund of the K.U.Leuven (OT 97/40). illness and on the influence of these attitudes on the clients' functioning. We will use the construct of expressed emotion (EE) to chart the relationship in the professional caregiver-client dyad. In the second section, we will describe characteristics of low- and high-EE professional relationships and in the third offer some tools for improving the working relationship.

\section{THE PRESENCE AND INFLUENCE OF EXPRESSED EMOTION IN PROFESSIONAL-CLIENT DYADS}

Expressed emotion (EE) is a well-established and well-developed construct for charting and assessing social interactions between professional caregivers and clients. It refers to the amount of criticism, hostility, and emotional overinvolvement (EOI) of a formal or informal caregiver with respect to the patient. First developed in 1959 (Brown, 1959; Brown et al., 1958; 1962; 1972), its strength is that it is a reliable and robust predictor of the illness outcome of patients with a broad range of severe psychiatric disorders and physical illnesses (Wearden $e t$ al., 2000). This means that patients living in high-EE environments (high criticism, presence of hostility and/or presence of EOI) have three to five times more risk of relapsing than do patients living in low-EE environments. Many family intervention programmes have been developed on the basis of the results of EE research and have components like psycho-education, problem-solving skills, and communication skills. Although not all of these programmes are successful, they can reduce the relatives' high-EE score and thus the patients' relapse rates (Barbato \& D'Avanzo, 2000; Dixon et al., 2000; Pilling et al., 2002).

Generally, EE is assessed with the Camberwell Family 
Interview (CFI)(Brown \& Rutter, 1966; Leff \& Vaughn, 1985; Vaughn \& Leff, 1976). The CFI, which is considered to be the best EE instrument (Kazarian, 1992; Van Humbeeck et al., 2002a), is a semi-structured interview that gathers factual and attitudinal information about the onset and development of the current illness episode, the illness history, irritability and quarrelling, the patient's symptomatology, and the quality of the relationship. A qualified rater then codes the audiotaped CFI on five scales: (1) critical comments (a frequency count), (2) hostility (a 4-point scale: $0-3$ ), (3) positive remarks (a frequency count), (4) EOI (a 6-point scale: 0-5) and (5) warmth (a 6-point scale: 0-5). Relatives are classified as high on the EE index if they make six or more critical comments, if they are hostile (score 1-3), and/or if they have a score of three or more on the EOI scale. However, because using the CFI is time consuming, alternative measurement instruments have been developed (review see Kazarian, 1992; Van Humbeeck et al., 2002a).

In the 1980s, researchers observed that professional caregivers could present behaviour that resembles the high- and low-EE attitudes of family members (Berkowitz \& Heinl, 1984; Cournos, 1987; Simpson, 1989). Thereupon, Watts (cited in Kuipers \& Moore, 1995) and Herzog (1992) succesfully used the EE construct to describe interaction patterns between professional caregivers and clients.

Although the EE-research in professional caregiverclient dyads still is in its infancy, there is evidence for high-EE attitudes towards clients with a broad range of psychiatric problems and even towards clients with learning disabilities (Ball et al., 1992; Barrowclough et al., 2001; Cottle et al., 1995; Finnema et al., 1996; Hansen et al., 1991; Moore \& Kuipers, 1992, 1999; Moore et al., 1992a; Oliver \& Kuipers, 1996; Sabarese, 1999; Snyder et al., 1994; Stark \& Siol, 1994; Tattan \& Tarrier, 2000; Van Humbeeck et al., 2001; in press; Weigel \& Collins, 2000; Willets \& Leff, 1997). In these studies, high-EE varies from $0 \%$ (Barrowclough et al., 2001) to $62 \%$ (Herzog, 1992). The differences in service facilities (residential care, hostels), client groups (chronic psychiatric clients, clients with schizophrenia), and EE assessment (CFI or other instruments) may account for the differences in high-EE scores.

Professional caregivers express the same amount of criticism and hostility as do family members, but they make fewer positive remarks and the amount of EOI differs. Professional caregivers are significantly less emotionally overinvolved than family members (Ball et al., 1992; Moore et al., 1992b). Only Stark \& Siol (1994) and Van Humbeeck et al. (2001) found evidence for the pres- ence of EOI. The absence of EOI is probably a consequence of the caregivers' professional background, their high caseloads, and the lower contact frequency and intensity. Nevertheless, Van Humbeeck et al. (2001) found attitudes that could be characterised as emotional overinvolvement behaviours and considered them due to role confusion, which they considered due to insufficient professional distance between professional caregiver and clients: the boundaries between the professional caregivers' professional and private spheres became blurred.

In family research, the construct has proved to be a reliable and robust predictor of relapses. Although the research in this field is still in its infancy, high-EE in client-professional caregiver dyads seems to have a negative influence on the clients' functioning and the clients' quality of life (Ball et al., 1992; Snyder et al., 1994, Finnema et al., 1996; Tattan \& Tarrier, 2000).

\section{CHARACTERISTICS OF LOW AND HIGH-EE RELATIONSHIPS}

More in-depth content analyses of low and high-EE responses showed that professional relationships differ from others more than by the presence or absence of criticism, hostility, and EOI. Therefore, researchers have tried to distinguish low and high-EE relationships and to describe these relationships (table I). Low-EE professionals can control their own feelings and are warm and able to motivate clients (Kuipers \& Moore, 1995). They maintain a good balance between over- and understimulating clients and offer support at the clients' own pace (Moore et al., 1992b). They understand clients' difficulties and motivate them to be as independent as possible. Compared with high-EE professionals, low-EE professionals try more to restore hope in clients. This means that they believe in the clients' abilities to overcome and to cope with the illness. High-EE professionals, on the contrary, tend to have unrealistic expectations about the clients' progress (Moore \& Kuipers, 1992). Moore \& Kuipers (1992) also suggested that low-EE professionals made more supportive statements on an interactional task than did their high-EE counterparts. They also focused more on positive aspects while the high-EE professionals tended to stress the clients' shortcomings.

Low-EE professional caregivers can establish clear boundaries: 'We are indeed a bit detached from our clients. But we need this distance because otherwise we would no longer be objective as regards offering proper care and activating clients.' This establishment of boundaries is a very important key feature of low-EE pro- 
Table I. - Characteristics of a low-EE enviroment.

In a low-EE environment, counsellors are characterized by

- a good equilibrium between over- and understimulation

- tolerancy towards negative symptoms and disturbed behavior

- clear boundaries (involved but not overinvolved)

- warm attitudes towards clients

- the ability to restore hope

- attention to the clients' perspective

- a lot of respect towards the clients

- expression of criticism in a way that clients can handle this

- openness and flexibility

- concern about the clients

- interest in the clients

- encouragement of clients to express their feelings

- understanding of the clients' illness

- attribution of problematic behaviours as uncontrollable and external to clients

fessionals. One professional caregiver stated that she had to turn over her client to another counsellor because $I$ felt that I had became too involved. This was going to be bad for me as well as for the client so I decided to change counsellors for a few days as I tried to establish clear boundaries between him and me.'

Another difference between high and low-EE professionals is in the education level. The two studies that covered this factor reported that less trained staff made significantly more critical comments than did more trained staff (Barrowclough et al., 2001; Van Humbeeck et al., 2002b).

In family research, Hooley \& Hiller (2000) and Leff \& Vaughn (1985) reported that openness could be a core characteristic of low-EE persons. This was affirmed in staff research (Moore et al., 1992b; Van Humbeeck et al., 2002b). In the study of Van Humbeeck et al. (2002b), openness was defined as being curious about new situations. This means that an open person does not necessarily conform to existing rules but tries to adapt to the situation. Openness is similar to flexibility. Indeed, in-depth content analyses of the CFI transcripts gives evidence that low-EE professionals take the clients' perspectives into account and adapt their interventions in function of the client and the client's state of mind. This, however, implies that the professional caregiver gets to know the client: 'I'm getting to know her. Now that I know her, it makes it easier for me to counsel her and to initiate the proper intervention. Now that I know that she needs reassurance I can offer it to her!' In addition, low-EE professional caregivers do not press or compel clients to do things: 'If I would require him to attend a day activity centre, he would be very unhappy and probably would relapse.'

An area that promises greater understanding of $E E$ is that of attributions. As in family research (Barrowclough et al., 1996; Bentsen et al., 1997; Hooley, 1998; Wendel et al., 2000), differences between high- and low-EE professionals can be explained by the way they attribute and interpret clients' symptoms. Indeed, when caregivers consider clients' symptoms to be controllable, internal to the client, or stable, they are significantly more critical and hostile than when they consider them to be non-controllable, external to the client, or unstable (and thus as a part of the clients' illness) (Barrowclough et al., 2001; Moore et al., 1992b).

EE research has shown that the counselling of clients with a severe mental illness is not always self-evident. Some professional caregivers show high-EE attitudes, role confusion can occur, and some are very insecure and uncertain about the best way to deal with clients.

More generally, it is found that professional caregivers can be subject to burnout (Brown \& O'Brien, 1998; Levert et al., 2000) and low feelings of personal accomplishment (Van Humbeeck, unpublished doctoral thesis). A reduced sense of personal accomplishment goes together with feelings of insufficiency and self-doubt, which ultimately leads to burnout. It is likely that these feelings can affect other members of the counselling team or negatively influence the clients' functioning.

\section{IMPLICATIONS FOR STAFF EDUCATION}

In this section, tools are offered for dealing with these clients on three levels: (1) the level of structured training and education programmes, (2) the team level, and (3) the individual level.

In view of the success of family intervention programmes, two training intervention programmes for professional caregivers were set up that focussed on the professional caregivers' attitudes towards clients (Baxter $e t$ al., cited in Senn et al. 1997; Finnema et al., 1996; Willets \& Leff, 1997). 
The training programme of Baxter \& Leff (cited in Senn et al., 1997) and Willetts \& Leff (1997) was based on the 'Thorn Initiative' course (Lam et al., 1993). This course, developed for community psychiatric nurses, contained a module about working with families of patients with schizophrenia. The nurses were taught to reduce the families' EE. Because this programme was very successful, it was modified to make it suitable for staff. The modified staff programme included topics like introduction to mental illness (symptoms and treatment possibilities), problem-solving skills, communication skills, and different coping strategies. Although the course was evaluated positively and perceived as being very useful, there was no significant difference in the presence of high-EE before and after the training programme.

A second attempt to influence professionals' EE was made by the group of Finnema et al. (1996). Their programme consisted of seven training days over a period of 14 weeks. Two months after the completion of the programme, three more half-day sessions were held. There were two baseline and two post-intervention measurements. Despite the increase of the nurses' knowledge, once again the EE level did not significantly change, although the ward atmosphere did. More specifically, there was a strong decrease in the number of ward rules and in the use of locked seclusion.

A number of reasons could account for the failure to reduce the professional caregivers' EE levels (Finnema et al., 1996; Willets \& Leff, 1997). First, both studies were pilot studies with a very small number of professional caregivers. Second compared with family programmes, the programmes were very limited in time. The developers of the programmes suggest that it would be unlikely for people to change significantly after such a short period. Third, the courses contained too many knowledgecontent sessions. It would be better to decrease such sessions and to give more attention to sessions in which critical and hostile attitudes could be tackled and discussed, perhaps by role-playing. Fourth, Finnema et al. (1996) stated that the focus on EE probably is too narrow, and that one must also focus on other aspects like changes in ward atmosphere. Fifth, we have the impression that these training programmes for professional caregivers were insufficiently tailored to the needs and preferences of these professionals. The programmes in these studies mimicked too closely the programmes for family mem- bers. If an educational programme is intended to influence the participants' behavior, attitudes, and knowledge, it should start with an inventory of these participants' learning needs, and the content, methods, and learning strategies should be tailored to those needs. Longer programmes where professional caregivers are actively involved in all the stages of the development of the education programme would probably be more successful.

Obviously, not all staff members will have an opportunity to attend standardised training and education programmes. For this reason, staff support, intervision, and supervision are good alternatives. Indeed, staff support and staff meetings can be very successful vehicles for ventilating fear, anger and frustration about clients (Kuipers \& Moore, 1995) and for increasing group cohesion and appreciation (Acker, 1999; Reid et al., 1999; Shafer et al., 1999). Professional caregivers can share experiences (positive as well as negative ones) and skills with their colleagues. In these process meetings, there is more time than in the usual team meetings for discussing specific problem cases and for exchanging individual reactions and experiences. Research has indicated that team members are highly appreciated sources of support that can alleviate feelings of burnout. Kuipers \& Moore (1995) also call for limited caseloads and regular reviews of clients' progress.

EE research does not imply or suggest that professional caregivers may never be critical towards the clients. On the contrary, criticism sometimes may be necessary to improve the clients' level of functioning or maintain its current level (Kanter et al., 1987). This was demonstrated in the intervention programme of Gelfand et al. (1967) in which professional caregivers had to respond to problematic behaviour by being warm and supportive. Criticism was not allowed. This working strategy did not decrease the clients' problematic behaviour! Therefore, we argue for a controlled use of criticism tailored to the clients' ability to receive it. This means that when professional caregivers judge that they need to criticise clients they should first consider how to convey this criticism (e.g., encouragingly, firmly, friendly, first the positive aspects and then the negative ones, with humour). Thus professional caregivers need to find the right dosage, expression forms, and time to provide this criticism. By taking these guidelines into account, the quality of care can be improved. 


\section{REFERENCES}

Acker G.M. (1999). The impact of clients' mental illness on social workers' job satisfaction and burnout. Health and Social Work 24(2), 112-119.

Ball R.A., Moore E. \& Kuipers, L. (1992). Expressed Emotion in community care staff. A comparison of patient outcome in a nine month follow-up of two hostels. Social Psychiatry and Psychiatric Epidemiology 27, 35-39.

Barbato A. \& D'Avanzo B. (2000). Family interventions in schizophrenia and related disorders: a critical review of clinical trials. Acta Psychiatrica Scandinavica 102, 81-97.

Barrowclough C., Tarrier N. \& Johnston M. (1996). Distress, expressed emotion, and attributions in relatives of schizophrenia patients. Schizophrenia Bulletin 22(4), 691-702.

Barrowclough C., Haddock G., Lowens I., Connor A., Pidliswyi J. \& Tracey N. (2001). Staff expressed emotion and causal attributions for client problems on a low security unit: An exploratory study. Schizophrenia Bulletin 27(3), 517-526.

Bentsen H., Munkvold O.G., Notland T.H., Boye B., Lersbryggen A.B., Oskarsson K.H., Uren G., Ulstein I., Bjorge H., Berg-Larsen R., Lingjaerde O. \& Malt \& U.F. (1997). Relatives' locus of control and expressed emotion in schizophrenia and related psychoses. British Journal of Clinical Psychology 36, 555-567.

Berkowitz R. \& Heinl P. H. (1984). The management of schizophrenic patients: the nurses' view. Journal of Advanced Nursing 9, 23-33.

Brown C. \& O'Brien K.M. (1998). Understanding stress and burnout in shelter workers. Professional Psychology: Research and Practice 29(4), 383-385.

Brown G.W. (1959). Experiences of discharged chronic schizophrenic mental hospital patients in various types of living groups. Millbank Memorial Fund Quarterly 37, 105-131.

Brown G.W. \& Rutter M. (1966). The measurement of family activities and relationships: A methodological study. Human Relations 19 , 241-263.

Brown G.W., Carstairs G.M. \& Topping, G. (1958). Post-hospital adjustment of chronic mental patients. Lancet ii, 685-689.

Brown G.W., Monck E.M., Carstairs G.M. \& Wing J.K. (1962), Influence of family life on the course of schizophrenic illness. British Journal of Preventive and Social Medicine 16, 55-68.

Brown G.W., Birley J.L.T. \& Wing J.K. (1972). Influence of family life on the course of schizophrenic disorders: A replication. British Journal of Psychiatry 121, 241-258.

Cottle M.. Kuipers L., Murphy G. \& Oakes P. (1995). Expressed emotion, attributions and coping in staff who have been victims of violent incidents. Mental Handicap Research 8(3), 168-183.

Cournos F. (1987). The impact of environmental factors on outcome in residential programs. Hospital and Community Psychiatry 38(8), 848-852.

Dietzel L. C. \& Coursey R.D. (1998). Predictors of emotional exhaustion among nonresidential staff persons. Psychiatric Rehabilitation Journal 4, 340-348.

Dixon L., Adams C. \& Lucksted A. (2000). Update on family psychoeducation for schizophrenia. Schizophrenia Bulletin 26(1), 5-20.

Finch E. S. \& Krantz S.R. (1991). Low burnout in a high-stress setting: A study of staff adaptation at Fountain House. Psychosocial Rehabilitation Journal 14(3), 15-26

Finnema E.J., Louwerens J.W., Slooff C.J. \& van den Bosh R.J. (1996). Expressed emotion on long-stay wards. Journal of Advanced Nursing 24, 473-478.

Gelfand D.M., Gelfand S. \& Dobson W.R. (1967). Unprogrammed reinforcement of patients' behaviour in a mental hospital. Behavioral Research Therapy 5, 201-207.

Hansen J.C., Berman S.P. \& Babcock C.W. (1991). The relationship of family and staff expressed emotion to residents' functioning in community residences. Psychosocial Rehabilitation Journal 14(4), 85-89.

Herzog T. (1992). Nurses, patients and relatives: a study of family pat- terns on psychiatric wards. In Family Intervention in Schizopltrenia Experiences and Orientations in Europe (ed. C.L. Cazzullo \& G. Invernizzi). ARS: Milan.

Hooley J. (1998). Expressed Emotion and locus of control. Journal of Nervous and Mental Disease 186, 374-378.

Hooley J.M. \& Hiller J.B. (2000). Personality and Expressed Emotion. Joumal of Abnormal Psychology 109(1), 40-44.

Kanter J., Lamb H.R. \& Loeper C. (1987). Expressed Emotion in families: A critical review. Hospital and Community Psychiatry 38(4), 374-380.

Kazarian S.S. (1992). The Measurement of Expressed Emotion: A Review. Canadian Journal of Psychiatry 37, 51-56.

Kuipers E. \& Moore E. (1995). Expressed Emotion and staff-client relationships. Implications for community care of the severely mentally ill. International Journal of Mental Health 24(3), 13-26.

Lam D.H., Kuipers L. \& Leff J.P. (1993). Family work with patients suffering from schizophrenia: the impact of training on psychiatric nurses' attitude and knowledge. Journal of Advanced Nursing 18 , 233-237.

Leff J. \& Vaughn C. (1985). Expressed Emotion in Families. Guilford Press: New York.

Levert T., Lucas M. \& Ortlepp K. (2000). Burnout in psychiatric nurses: Contributions of the work environment and a sense of coherence. South African Joumal of Psychology 30(2), 36-43.

Moore E. \& Kuipers L. (1992). Behavioral correlates of expressed emotion in staff-patient interactions. Social Psychiatry and Psychiatric Epidemiology 27, 298-303.

Moore E. \& Kuipers E. (1999). The measurement of expressed emotion in relationships between staff and service users: The use of short speech samples. British Journal of Clinical Psychology 38, 345-356.

Moore E., Ball R. A. \& Kuipers L. (1992a). Expressed emotion in staff working with the long-term adult mentally ill. British Journal of Psychiatry 161, 802-808.

Moore E., Kuipers L. \& Ball R. (1992b). Staff-patient relationships in the care of the long-term adult mentally ill. A content analysis of Expressed Emotion interviews. Social Psychiatry and Psychiatric Epidemiology 27, 28-34.

Oliver N. \& Kuipers E. (1996). Stress and its relationship to expressed emotion in community mental health workers. International Journal of Social Psychiatry 42(2), 150-159.

Pilling S., Bebbington P., Kuipers E., Garety P., Geddes J., Orbach G \& Morgan C. (2002). Psychological treatments in schizophrenia: I. Meta-analysis of family intervention and cognitive behaviour therapy. Psychological Medicine 32 (5), 763-782.

Reid Y., Johnson S., Morant N., Kuipers E., Szmukler G., Bebbington,P., Thornicroft G. \& Prosser D. (1999). Improving support for mental health staff: a qualitative study. Social Psychiatry Psychiatric Epidemiology 34, 309-315.

Sabarese J.A. (1999). Expressed emotion and mental retardation. Dissertation Abstracts International 59(8), 4483-B.

Senn V., Kendal R., Willetts L. \& Trieman N. (1997). Training level and training needs of staff. In Care in the Community. Illusion or Reality (ed. J. Leff), pp. 137-144. Wiley: Chichester.

Shafer M.S., Pardee R. \& Stewart M. (1999). An asssessment of the training needs of rehabilitation and community mental health workers in a six-state region. Psychiatric Rehabilitation Journal 23(2), 161-169.

Simpson R.B.C. (1989). Expressed emotion and nursing the schizophrenic patient. Journal of Advanced Nursing 14, 459-466.

Snyder K.S., Wallace C.J., Moe K. \& Liberman R.P. (1994). Expressed Emotion by residential care operators and residents' symptoms and quality of life. Hospital and Community Psychiatry 45(11), 1141-1143.

Stark F.-M. \& Siol T. (1994). Expressed emotion in the therapeutic relationship with schizophrenic patients. European Psychiatry 9, 299 303

Tattan T. \& Tarrier N. (2000). The expressed emotion of case managers of the seriously mentally ill: the influence of expressed emotion on clinical outcomes. Psychological Medicine 30, 195-204 
Van Humbeeck G., Van Audenhove Ch., Pieters G., De Hert M., Storms G., Vertommen H., Peuskens J. \& Heyrman J. (2001). Expressed emotion in staff-patient relationships: The professionals' and residents' perspectives. Social Psychiatry and Psychiatric Epidemiology 36, 486-492.

Van Humbeeck G., Van Audenhove Ch., De Hert M., Pieters G. \& Storms G. (2002a). Expressed emotion: a review of assessment instruments. Clinical Psychology Review 22(3), 321-341.

Van Humbeeck G., Van Audenhove Ch., Pieters G., De Hert M., Storms G., Vertommen H., Peuskens J. \& Heyrman J. (2002b). Expressed emotion in the resident - professional caregiver dyad: are symptoms, coping and personality related. Social Psychiatry and Psychiatric Epidemiology 37, 364-371.

Van Humbeeck G., Van Audenhove Ch., Pieters G., De Hert M., Storms G., Vertommen H., Peuskens J. \& Heyrman J. (in press). Expressed emotion in professional caregivers' relations with residents with learning disabilities. Towards a new definition of emotional overinvolvement. European Journal on Mental Disabilities.
Vaughn C.E. \& Leff J.P. (1976). The influence of family and social factors on the course of psychiatric illness. A comparison of schizophrenic and depressed neurotic patients. British Journal of Psychiatry $129,125-137$.

Wearden A.J., Tarrier N., Barrowclough C., Zastowny T.R. \& Rahill A.A. (2000). A review of expressed emotion research in health care. Clinical Psychology Review 20 (5), 633-666.

Weigel L. \& Collins L. (2000). Staff attributions and expressed emotion about a client with challenging behaviour. Journal of Intellectual Disability Research 44, 515.

Wendel J.S., Miklowitz D.J., Richards J.A. \& George E.L. (2000). Expressed emotion and attributions in the relatives of bipolar patients: An analysis of problem-solving interactions. Journal of Abnormal Psychology 109(4), 792-796.

Willetts L.E. \& Leff J. (1997). Expressed emotion and schizophrenia: the efficacy of a staff training programme. Journal of Advanced Nursing 26 (6): 1125-1133 